\title{
Importance of Mathematics Laboratories in High School Leveal
}

\author{
khasim pasha $\mathrm{sd}^{1}$,Nalla Janardhan $\mathrm{Rao}^{2}, \mathrm{P}$. Veerababu ${ }^{3}$ \\ 1,3 Assistant Professors, Department of Mathematics, KITS, Khammam, A.P., India. \\ 2 Assistant Professor, Department of, Mathematics, RJC, Khammam, A.P., India.
}

\begin{abstract}
This research paper deals the importance's of mathematics laboratory in teaching mathematics in high school mathematics. A total of 200 Mathematics students were involved in the study. The study is a quasiexperimental research. Results were analyzed using mean, standard deviation and analysis of covariance. It was observed that the use of mathematics laboratory enhanced achievement in mathematics. This results also showed that no significant difference exists in the achievement of male and female mathematics students taught with mathematics laboratory. By implementing this we are given more knowledge to students by concrete scene.

Key words: High school students, plane geometry, methodology class, mathematics aids.
\end{abstract}

\section{Introduction}

Mathematics is the foundation of science and technology and the functional role of mathematics to science and technology is multifaceted and multifarious that no area of science, technology and business enterprise escapes its application (Okereke, 2006). Ukeje (1986) described mathematics as the mirror of civilization in all the cent- uries of painstaking calculation, and the most basic discipline for any person who would be truly educated in any science and in many other endeavours. Despite the importance placed on mathematics, rese- archers (Odili, 1986; Salau, 1995; Amazigo, 2000; Agw- agah, 2001; Betiku, 2001; Obioma, 2005; Maduabum and Odili, 2006; Okereke, 2006) had observed that stud-ents lack interest in the subject and perform poorly in it. Ukeje (1986) observed that mathematics is one of the most poorly taught, widely hated and abysmally understood subject in secondary school, students particularly girls run away from the subject. The West African Examination Council (WAEC) Chief Examiners [2003, 2004, 2005, and 2006] consistently reported candidates' lack of skill in answering almost all the questions asked in general mathematics. WAEC Chief Examiners [2003, 2005] further observed that candidates were weak in Geometry of circles and 3dimensional problems. According to their reports, most candidates avoided questions on 3-dimensional problem, when they attempt geometry questions; only few of the candidates showed a clear understanding of the problem in their working. WAEC [2004] also reported candidates' weakness in Algebraic expression and word problems among others. Obioma (1985), Obodo (1993) and Okereke (2006) reported gender as a significant factor in mathematics achievement and Onwioduokit and Akinbobola (2005) reported it as a significant factor in physics achievement when physics students are taught with advance orga- nizers. However Okonkwo (1997) reported gender as non significant when students are taught with tangram puzzle game. Okereke (2006) attributed students' poor perfo- rmance to factors such as the society view that mathe- matics is difficult, shortage of qualified teachers, lack of mathematics laboratory and lack of incentive. The abstract nature of mathematics should be reduced through demonstration and practical methods. Agwagah (1997) observed that the problem of ineffective teaching can be tackled through planned and intelligent application of the mathematics laboratory. Thus Agwagah recomm- ended the use of laboratory approach to the study of mathematics. The method of drill and verbal recitation makes learning boring and lacks motivation for further learning. Srinivasa (1978) had earlier recommended the use of mathematics laboratory in teaching mathematics. According to Srinivasa, this will lead the students to formation of concepts out of experiences with discrete objects. In this casethe vague theories and imaginary objects take real shape and the students understand better and perform better. It is important therefore to consider strategies that may help to improve the performance, with the view of considering their effect on teaching and learning of mathematics. Such strategies include the use of mathematics laboratory (Ogunkunle, 2000). Mathematics laboratory is a place where students can learn and explore various mathematical concepts and verify different mathematical facts and theories using varieties of activities and material (Igbokwe, 2000). The use of mathematics laboratory helps to integrate theory and practical work in mathematics teaching /learning. Ohuche (1990) advocated the need for moderately equipped mathematics laboratories. Ogunkunle (2000) itemized the advantages of using mathematics laboratory which include;

o Display mathematical information

o Avenue for experimentation through practical work

o Pool of storage of mathematical materials for easy access

o Removing abstractness and increasing effective teaching /learning. Based on the advantages of mathematics laboratory, it is expected that teaching and learning of mathematics with mathematics laboratory may help to reduce the abstract nature of the subject and draw the students to follow. 


\section{Statement of the content}

Evidence of poor performance in mathematics by secondary school students point to the fact that the most desired technological, scientific and business application of mathematics cannot be sustained. This makes it paramount to seek for a strategy for teaching mathematics that aims at improving its understanding and performance by students. Evidence abound (Srinivasa, 1978; Ogunkunle, 2000), that lack of mathematics laboratory and Mathematics teachers non-use of laboratory technique in teaching mathematics is one of the major factors that contribute to poor achievement in mathematics by secondary school students. Therefore the study is designed to find out the effects of using mathematics labo- ratory in teaching on the achievement of High school mathematics students( HSS).

\section{Purpose of the study}

The purpose of this study is to investigate the effects of using mathematics laboratory in teaching students HSS in mathematics. Specifically, the study sought the following;

o To investigate the extent to which the use of mathematics laboratory will enhance the achievement of mathematics students.

o To compare the achievement of male and female mathematics students taught with mathematics laboratory.

\section{Purpose of the study}

The purpose of this study is to investigate the effects of using mathematics laboratory in teaching JSS students in mathematics. Specifically, the study sought the following;

To investigate the extent to which the use of mathematics laboratory will enhance the achievement of mathematics students.

To compare the achievement of male and female mathematics students taught with mathematics labora tory.

\section{Research questions}

1. To what extent does the use of mathematics laboratory affects the achievement of mathematics students?

2. Is there any significant difference between the achievement of male and female mathematics students taught with mathematics laboratory?

\section{Research hypotheses}

Ho1: There is no significant difference in achievement of mathematics students taught with mathematics laboratory and those taught with lecture method $(\mathrm{P}<0.05)$.

Ho2: There is no significant difference in the achievement of male and female mathematics students taught with mathematics laboratory $(\mathrm{P}<0.05)$.

\section{Research design}

The study is a pre-test post-test nonrandomized equivalent group design.

Population

The population was made up of all the JSS III mathematics students in the secondary schools in Ekwusigo Local Government Area of Anambra State.

\section{Sample and sampling technique}

A total of one hundred (100) students were used for the study. Ekwusigo Local Government Area has only two co-educational schools and these were purposively selected. One arm of 50 JSS III students was randomly selected from each of the co-educational school. One class was assigned to treatment group A, fifty in number ( 23 boys and 27 girls) and the other class was assigned to control group B, fifty in number (17 boys and 33 girls).

\section{Instrument and validation}

The researchers used the Mathematics Achievement Test (MAT) as an instrument. Also, Designed Math matics Laboratory (DML) and the lesson plan were used as instructional tools for the study.

MAT: This is a ten-item achievement test constructed by the researchers based on the JSIII mathematics syllabus in the area of plane geometry and algebraic expressions. The test was in essay form written to cover the areas of knowledge, comprehension and application levels. The same MAT was used for pretest and posttest treatment but the colour of the paper for posttest was changed from white to yellow. The validity of the items was assessed by three mathematics education experts and two experienced secondary school mathematics teachers. The instrument was trial tested with 40 students in a school not participating in the study but within the same area of study. The Kunder Richardson formular (21 was used to establish the coefficient of internal consistency for the instrument (MAT) and the value is 0.75 .

DML: The Laboratory was designed to have a typical laboratory building with necessary fittings and equipment which include Geoboard, graph board, Pythagoras triple triangle, Skeletal globe, Abacus, close and open cylinders, cone, conic sections, rectangular and triangular pyramid, cube, graphic calculator, computer system 
etc. This was looked into by three mathematics education experts to ensure its suitability and representation of a true mathematics laboratory.

Lesson plan: The plan was written in two forms.

- Plan that used the DML as a teaching material for teaching the treatment group A.

- Ordinary lesson plan used in conventional classroom for group B.

\section{Research procedure}

Group A $(n=50)$ were taught plane geometry and algebraic expressions using DML as a teaching material while group $B(n=50)$ were taught the same topics without mathematics laboratory but with lecture method using ordinary lesson plan. The teaching in both schools which took four weeks was done by the researchers. This was concurrently done for both groups. One taught the students in both groups and examined them while the other marked their scripts compiled results and this helped in controlling teacher variable. To solve the problem of interclass discussion among the students, one intact class in each school was used only. More so, the experiment lasted for four weeks and it was expected that this period was long enough as not to permit the pre-test to affect the post-test scores and the items were re- arranged before administering the posttest.

\section{Research question one}

\section{RESULTS}

1. To what extent does the use of mathematics laboratory affects the achievement of mathematics student? The analysis is shown on Table 1.

2. The gain in achievement of students in experimental group is 27.9 while that of control group is 14.8 with mean difference of 13.1

\section{Research question two}

Is there any significant difference between the achievement of male and female mathematics students taught with mathematics laboratory? The analysis is shown on Table 2. The mean gain for the female group (28.9) is higher than mean gain of the male group (26.8) with a mean difference of 2.1

\section{Hypothesis one (Ho1)}

There is no significant difference in achievement of mathematics students taught with mathematics labora- tory and those taught with lecture method. The analysis is presented in Table 3. The null hypothesis was therefore rejected. Hence, there was a significant difference in achievement of mathematics students taught with mathematics laboratory and those taught with lecture method.

\section{Hypothesis two (Ho2)}

There is no significant difference in achievement of male and female mathematics students taught with mathematics laboratory. The analysis is shown on Table 4 . The null hypothesis was not rejected. There was no significant difference in achievement of male and female mathematics students taught with mathematics laboratory

\section{Discussion Of Results}

Results of research question one showed that students taught mathematics with mathematics laboratory achieved more than those taught without mathematics laboratory. This was tested in hypothesis one which revealed that a significant difference exist between the achievement of students taught mathematics with mathematics laboratory and those taught with lecture method. This was in favors of mathematics laboratory group. This finding is supported by Srinivasa (1978), where they highlighted the advantages of using mathematics laboratory in teaching to include providing opportunity for student to understand and internalize the basic mathematical concepts. In this way the students achieved better than otherwise. The results from research question two showed that boys had a mean gain of 26.8 while girls had a mean gain of 28.9. This was tested in hypothesis two. Results from this hypothesis showed that there was no significant difference in achievement of male and female mathematics students taught with mathematics laboratory. This finding is in line with the findings of Okonkwo (1997) who reported that students' gender has no significant effect on their achievement when taught with tangram puzzle game. However, the finding disagrees with the findings of Obioma (1985), Obodo (1993) and Okereke (2006). They reported gender as a significant factor in achievement when mathematics is taught with certain strategies/techniques. Onwioduokit and Akinbobola (2005) also reported gender as significant factor in physics achievement when taught physics with pictorial and written advance organizers.

Conclusion Based on the findings in this study, the following conclusions were drawn:

- Students taught with mathematics laboratory achieved better than those taught without it.

- There exists no significant difference in achievement of male and female mathematics students taught with mathematics laboratory. 
TABLE (1)

Mean mathematics achievement scores of treatment and control, out of 200 student taken 100only

\begin{tabular}{|l|l|l|l|}
\hline Group & Mean pre-test & Mean pos-test & Mean again \\
\hline Experimental, $(\mathrm{n}=50)$ & 22.6 & 50.5 & 27.6 \\
\hline Control, $(\mathrm{n}=50)$ & 19.9 & 34.7 & 14.6 \\
\hline Mean difference & 2.7 & 15.7 & 13.1 \\
\hline
\end{tabular}

TABLE (2)

Mean mathematics achievement scores of male and female subjects in Experimental groups, out of 200 students taken 100only

\begin{tabular}{|l|l|l|l|}
\hline Group & Mean pre-test & Mean pos-test & Mean again \\
\hline Male, $(\mathrm{n}=50)$ & 24.9 & 51.7 & 26.8 \\
\hline Female, $(\mathrm{n}=50)$ & 20.6 & 49.5 & 28.9 \\
\hline Mean difference & 4.3 & 2.2 & -2.1 \\
\hline
\end{tabular}

.TABLE (3)

Covariance statistics for testing Hol

\begin{tabular}{|l|l|l|l|l|l|l|l|}
\hline Source of variance & df & ssx & ssy & ssxy & ssyx & mssyx & sdyx \\
\hline Between groups & 1 & 188 & 6342 & 1105 & 3853 & 3853 & \\
Within group & 96 & 11268 & 26993 & 4350 & 26885 & 274 & 16.6 \\
Total & 99 & 11456 & 33335 & 5455 & & & \\
& & & & & & & \\
\hline
\end{tabular}

FYX $=14.04=$ F-cal and F-crit $=3.94$

TABLE (4)

Covariance statistics for testing Ho2

\begin{tabular}{|l|l|l|l|l|l|l|l|}
\hline Source of variance & df & ssx & ssy & ssxy & ssyx & mssyx & sdyx \\
\hline Between groups & 1 & 5.12 & 426 & -46.7 & 447.7 & 447.7 & \\
Within group & 48 & 6193 & 9672 & 2701 & 8494 & 177 & 13.3 \\
Total & 49 & 6196 & 10099 & 2654 & & & \\
& & & & & & & \\
\hline
\end{tabular}

FYX $=2.53=$ F-cal $<$ F-crit $=4.04$

References:

[1]. Agwagah UNV (2001): The teaching of Number bases in Junior Secondary mathematics: The use of Base board. ABACUS: J. Math. Assoc. of Niger. (Mathematics Education Series) 26(1):1-7.

[2]. Amazigo JC.(2000): Mathematics PhobiaDiagnosis and Prescription. National Mathematical

[3]. Centre First Annual Lecture, Abuja,

[4]. July. Betiku OF (2001): Causes of Mass Failures in Mathematics Exam- inations among students. A Commissioned paper presented At Government Secondary School, Karu, Abuja Science Day, First March.

[5]. Obioma GO (1985) The Development and Validation of a Diagnostic Mathematics test for Junior Secondary Students. Unpublished doctorial dissertation, UNN. Obioma GO (2005) Emerging issues in mathematics education in Nigeria with emphasis on the strategies for effective teaching and learning of word problems and algebraic expression. J. issues Math. 8 (1), A Publication of the Mathematics Panel of the STAN, 1-8.

[6]. Obodo GC (1993) Science and mathematics Education in Nigeria (p. 120-136) Nsukka, The Academic Forum publisher. Salau MO (1995): Analysis of students' enrolment and performance in Mathematics at the senior secondary certificate level. J. Curriculum Studies.5\&6(1,2): $1-8$.

[7]. Srinivasa N (1978): A Laboratory for teaching mathematics. JSTAN 9(1): 22-24.

[8]. Obioma GO (2005) Emerging issues in mathematics education in Nigeria with emphasis on the strategies for effective teaching and learning of word problems and algebraic expression. J. issues Math. 8 (1), A Publication of the Mathematics Panel of the STAN, 18 .

[9]. Obodo GC (1993) Science and mathematics Education in Nigeria (p. 120-136) Nsukka, The Academic Forum publisher. Salau MO (1995): Analysis of students' enrolment and performance in Mathematics at the senior secondary certificate level. J. Curriculum Studies.5\&6(1,2): 1-8.

[10]. Srinivasa N (1978): A Laboratory for teaching mathematics. JSTAN 9(1): 22-24. 
PROFILES :

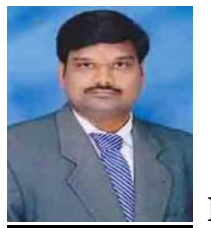

KHASIM PASHA SD was born in Khammam, Khammam Dt, Andhra Pradesh, India. He received M.Sc., in Mathematics from Kakatiya University, Warangal, Andhra Pradesh, India. Presently, he is pursuing M.Tech in C.S.E from Bomma Institute of Technology \& sciences, Allipuram, Khammam Dt, Andhra Pradesh, India. His Research interest

includes the important of mathematics to high level school ,and mathematics Aids

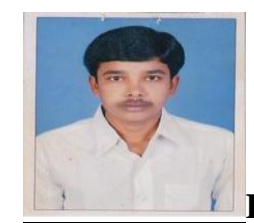

P.VEERA BABU was born in Khammam, Khammam Dt, Andhra Pradesh, India. He received M.Sc., in Mathematics from Osmania University, Hydrabed, Andhra Pradesh, India. His Research interest includes the important of mathematics to high level school ,and mathematics Aids .

Nalla Janardhan Rao was born in Khammam, Khammam Dt, Andhra Pradesh, India. He received M.Sc., in Mathematics from Osmania University, Hydrabed, Andhra Pradesh, India. His Research interest includes the important of mathematics to high level school , and mathematics Aids 